\title{
Truncal Vagotomy, Gastrojejunostomy and Braun Anastomosis Technique in the Surgical Treatment of Intractable Peptic Ulcer
}

\author{
Abdullah Yıldız \\ Department of General Surgery, University of Health Sciences, Umraniye Training and Research Hospital, Istanbul, Turkey
}

\begin{abstract}
Introduction: The present study aims to evaluate the results of bilateral truncal vagotomy (BTV), gastrojejunostomy (GJ) and Braun (B) anastomosis technique, which has been used in our patients with intractable peptic ulcer.

Methods: Demographics, indications of surgery (intractability, stenosis, refractory bleeding), diagnostic methods used (barium X-ray, upper gastrointestinal endoscopy), localization of ulcer, early and late postoperative complications, hospitalization period and mortality parameters of 32 patients, who underwent elective surgery (BTV+GJ with long afferent and efferent loops+B) in a two-year period, were retrospectively evaluated in this study.

Results: The mean age was 47 years (range, 29-73), and all of them were male (91\%) except three patients (9\%). The most common localization of ulcers was the first part of the duodenum at anterior wall (64.6\%). Resistance to the medical treatment and persistent symptoms (intractability, 34.4\%) and pyloric stenosis (31.3\%) were the most common indications for surgery. Early postoperative complications were surgical site infections (6.6\%), delayed gastric emptying (3.3\%) and atelectasis (3.3\%). All patients were discharged home between the 5th and 10th postoperative days. Gastric dullness, episodic diarrhea and Dumping syndrome $(15.3 \%, 11.5 \%$ and $7.7 \%$, respectively) were among the commonest late postoperative complications in a mean of 20 months follow-up period (range, 12-30). There was no mortality.

Discussion and Conclusion: Although ulcer surgery is rarely performed today, after introduction of modern anti-ulcer medications, we think that the BTV+GJ+B procedure can be applied safely in intractable cases.

Keywords: Braun anastomosis; gastrojejunostomy; intractable; peptic ulcer; truncal vagotomy.
\end{abstract}

$P^{e}$ eptic ulcer (PU) is described as a sore lesion extending at least to the muscularis mucosa, and it may develop anywhere in the gastrointestinal tract which contacts gastric acid ${ }^{[1-3]}$. The term PU disease (PUD) is commonly used for gastric and duodenal ulcers. However, it may develop at the distal esophagus, Meckel diverticulum (heterotopic gastric mucosa), anastomosis sites or distal bowel after gastric surgery, and anywhere of the digestive tract that contains heterotopic gastric mucosa ${ }^{[4,5]}$. Even medical treatment is the first-line therapy for the past two-three decades, complex conditions, such as intractability or pyloric stenosis may still require invasive interventions or surgical treatment.

From the historical point of view, PUD was primarily a surgical condition during the period in which the pharmaceuti-

Correspondence (İletişim): Abdullah Yıldız, M.D. Saglik Bilimleri Universitesi, Umraniye Egitim ve Arastirma Hastanesi, Genel Cerrahi Klinigi, Istanbul, Turkey

Phone (Telefon): +90 5322871866 E-mail (E-posta): ayildizster@gmail.com

Submitted Date (Başvuru Tarihi): 06.01.2020 Accepted Date (Kabul Tarihi): 20.01.2020

Copyright 2021 Haydarpaşa Numune Medical Journal

OPEN ACCESS This is an open access article under the CC BY-NC license (http://creativecommons.org/licenses/by-nc/4.0/) 
cal industry has not developed yet. In 1881, Billroth resected PU-related pyloric stenosis and used gastroduodenostomy for gastrointestinal continuity ${ }^{[5]}$. In the following years, this procedure was guided for anterior gastrojejunostomy (GJ) firstly and then posterior GJ, and then, Billroth had described Billroth 2 GJ method by burying the duodenum, which is currently used ${ }^{[5,6]}$. These methods shed light on the current development of modern gastric surgery.

Billroth I and II surgeries started to be used in the surgical treatment of PU in time, but GJ was performed alone from 1930 to 1960 because of high morbidity, mortality and high recurrence rates ${ }^{[5]}$. However, the disease's pathophysiological base has been questioned due to the incidence of recurrent ulcers up to $30 \%$ in the long term ${ }^{[4,5]}$. As a result of these studies, the role of vagus on acid secretion was determined, and vagotomy was started to be performed on PU patients ${ }^{[2-4,6]}$. However, due to gastric stasis problems seen after vagotomy, GJ was added to truncal vagotomy procedures to relieve gastric emptying problems in the following years ${ }^{[4,7]}$. Later on, pyloroplasty with different techniques was described. Today, these methods are still in use for intractable cases that do not respond to modern medical treatments, such as proton pump inhibitors and cause complications ${ }^{[5-7]}$.

In the present study, we aimed to evaluate the results of patients who underwent elective bilateral truncal vagotomy (BTV), GJ and Braun (B) anastomosis procedure because of intractable PU.

\section{Materials and Methods}

The data of 32 patients who underwent elective surgery due to duodenal ulcer between November 1987 and April 1989 at the General Surgery Clinic of Istanbul Göztepe Training and Research Hospital were collected retrospectively. All of our patients underwent elective anesthesia consultation and preoperative routine laboratory tests were performed before the procedure. Demographics, indications of surgery (intractability, stenosis, refractory bleeding), diagnostic methods used (barium X-ray, upper gastrointestinal endoscopy), localization of ulcer, early and late postoperative complications, hospitalization and follow-up periods and mortality were evaluated.

Surgical Procedure: BTV+GJ with long afferent and efferent loops+B (Fig. 1)- A midline median incision were used to explore the abdomen. After determining the localization and condition of the ulcer, the visceral peritoneum was opened on the anterior infra-diaphragmatic surface of the esophagus, the anterior vagus and its adjacent branches

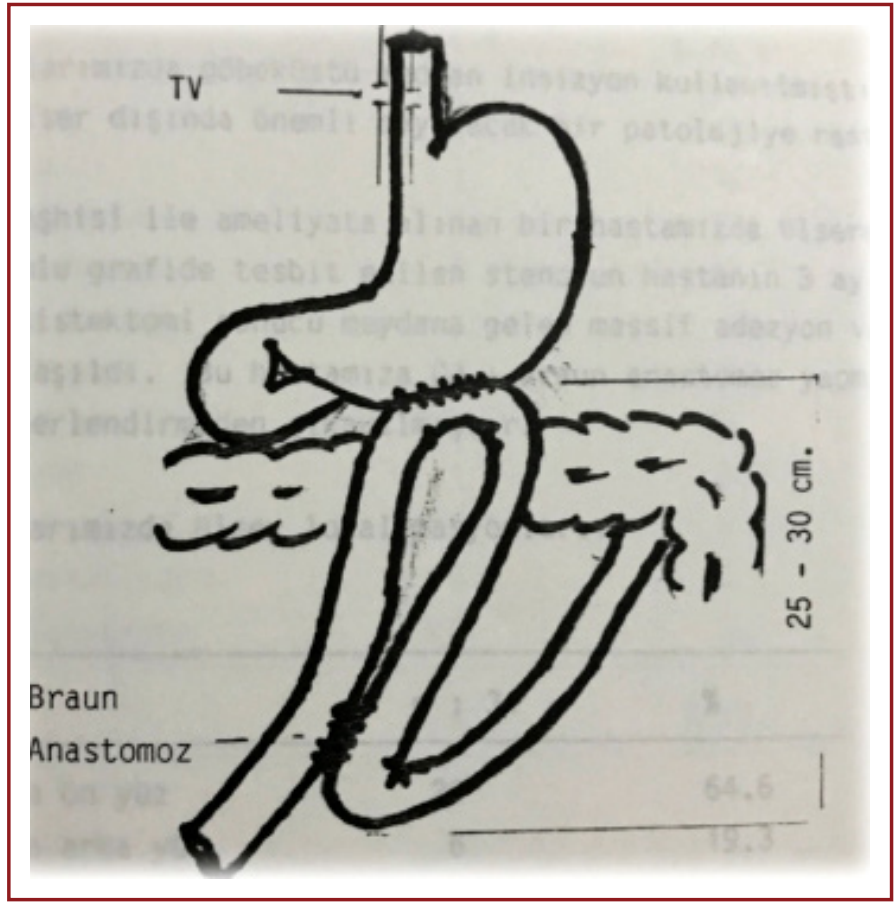

Figure 1. BTV+GJ with long afferent and efferent loops+B.

were cut and the same procedure was applied for the posterior vagus. Then, the transverse colon was lifted upwards to find the Treitz ligament. Antecolic, antegastric, iso or aniso-peristaltic double-layered anastomosis was created at 25-30 cm distance from the Treitz ligament. Then, Braun anastomosis with a 2-3 cm gap was performed in such a way that is ensuring no rotation or folding between the afferent and efferent loops of the jejunum. The opening on the mesentery was repaired and a drain was placed before the closure of the abdomen.

\section{Results}

The mean age of the 32 patients included in our study was 47.3 years (range, 29-73). The number of male patients was $29(91 \%)$ and the number of women was three (9\%). Concerning age distribution, most of the patients were between $29-35$ years and $36-40$ years $(40.6 \%$ and $18.8 \%$, respectively, Table 1).

Resistance to the medical treatment and persistent symptoms (intractability, 34.4\%) and pyloric stenosis (31.3\%) were the commonest surgical indications encountered (Table 2). The most common localization of ulcers was the first part of the duodenum at the anterior wall $(64.6 \%$, Table 3).

The nasogastric tubes were removed on postoperative days 3 to 6 . There were no complications of anesthesia and operative technique used during the operative period. 
Table 1. Distribution of our patients according to age groups

\begin{tabular}{lcc} 
Age & $\mathbf{n}$ & $\%$ \\
\hline $29-35$ & 13 & 40.6 \\
$36-40$ & 6 & 18.8 \\
$42-45$ & 4 & 12.1 \\
$46-50$ & 3 & 9.3 \\
$51-55$ & 1 & 3.1 \\
$56-50$ & 2 & 6.2 \\
$61-65$ & 2 & 6.2 \\
$66-70$ & - & - \\
$71-75$ & 1 & 3.1 \\
\hline
\end{tabular}

Table 2. Indications for surgery

\begin{tabular}{lcc} 
Indications & $\mathbf{n = 3 2}$ & $\%$ \\
\hline Intractability & 11 & 34.4 \\
Stenosis & 10 & 31.3 \\
Bleeding & 3 & 9.3 \\
Perforation & 2 & 6.2 \\
Bleeding + Stenosis & 5 & 15.9 \\
Bleeding + Perforation & 1 & 3.1 \\
\hline
\end{tabular}

Table 3. Localization of ulcers

\begin{tabular}{lcc} 
Localization & $\mathbf{n = 3 1}$ & \% \\
\hline First part of the duodenum anterior wall & 20 & 64.6 \\
First part of the duodenum posterior wall & 6 & 19.3 \\
Prepyloric-pyloric & 4 & 12.9 \\
Second part of the duodenum & 0 & 0 \\
Gastroduodenal & 0 & 0 \\
Kissing ulcer & 1 & 3.2 \\
\hline
\end{tabular}

Early postoperative complications were surgical site infections (wound and intraperitoneal infections, 6.6\%), delayed gastric emptying (3.3\%) and atelectasis (3.3\%) (Table 4). All patients discharged home between the $5^{\text {th }}$ and $10^{\text {th }}$ postoperative days. Gastric dullness, episodic diarrhea and Dumping syndrome $(15.3 \%, 11.5 \%$ and $7.7 \%$, respectively, Table 5) were among the commonest late postoperative complications in a mean of 20 months follow-up period (range, 12-30). There was no mortality.

\section{Discussion}

Epidemiologically, the average incidence of PUD in the community is $1-3 \%$ with male predominance ${ }^{[1,3]}$. PU may occur at any age. However, duodenal ulcers usually appear between ages 30 and 50 and are more common in men than women. Stomach ulcers tend to occur later in life, af-
Table 4. Early postoperative complications

\begin{tabular}{lcc} 
Complications & $\mathbf{n = 4}$ & $\mathbf{\% 1 3 . 2}$ \\
\hline Mortality & 0 & 0 \\
Wound infection & 1 & 3.3 \\
Intraperitoneal infection & 1 & 3.3 \\
G.E. anastomosis leakage & 0 & 0 \\
Bleeding & & \\
$\quad$ Intraperitoneal & 0 & 0 \\
$\quad$ Anastomosis & 0 & 0 \\
Gastric retention & 1 & 3.3 \\
Respiratory tract infection & 1 & 3.3 \\
Total & 4 & 13.2 \\
\hline
\end{tabular}

Table 5. Postoperative late complications

\begin{tabular}{lcc} 
& $\mathbf{n}$ & \% \\
\hline Recurrent Ulcer & - & - \\
Diarrhea & & \\
$\quad$ Chronic mild & - & - \\
$\quad$ Episodic mild & 2 & 7.7 \\
$\quad$ Chronic severe & - & - \\
$\quad$ Episodic severe & 1 & 3.8 \\
Dumping & & \\
$\quad$ Early & 2 & 7.7 \\
$\quad$ Late & - & - \\
Flatulence & 2 & 7.7 \\
Epigastric dullness & 4 & 15.3 \\
Vomiting & - & - \\
Pyrosis & 2 & 7.7 \\
Dysphagia & 1 & 3.8 \\
Abdominal pain & 1 & 3.8 \\
\hline
\end{tabular}

ter age 60 and affect women more often than men. In our series, 29-35 (40.6\%) and 36-40 (18.8\%) age groups were the majority. Moreover, $91 \%$ of our patients were male and the male-female ratio was 9:1. Demographic data was consistent with the literature reviewed ${ }^{[1-4]}$.

Either advances in the understanding of etiopathogenesis of PUD or high morbidity and mortality rates recorded after vagotomy resulted in a decrease in the popularity of resection and drainage procedures. Therefore, one of the attempts to prevent gastric stasis after vagotomy has been to provide passage by GJ. The main advantage of this method is that it can be performed without requiring resection. Although pyloroplasty has been described in the following years, gastroenterotomy (GE) anastomosis after truncal vagotomy procedure is still the most preferred procedure by many surgeons ${ }^{[3-7]}$. 
Even there is a sharp decrease in PUD surgery today, these surgical procedures are still in use for intractable cases that do not respond to modern medical treatments, such as proton pump inhibitors, and cause complications ${ }^{[5-7]}$. The literature reveals that intractability is the most common indication for surgical treatment before $1990^{[8-10]}$. Our data also conform to these rates. In our series, the most common indications for duodenal ulcer surgery were determined as intractability (34.4\%) and pyloric stenosis (31.3\%). These patients were on both proton pump and $\mathrm{H} 2$ receptor antagonists.

Some conditions that may occur after truncal vagotomy and gastroenterostomy procedure in duodenal ulcer may adversely affect the patient's quality of life. Sometimes, a new reconstructive intervention may be required. Complications, such as gastric atony, delayed emptying, obstruction, transient dysphagia, bleeding, drainage leakage, intraabdominal abscess, jaundice and pancreatitis, can be seen in the postoperative early period. Gastric atony and delayed emptying occur in $2-20 \%$ of patients as early complications $^{[11-16]}$. Edema, hematoma, anastomosis leakage, adhesions, pancreatitis, small-volume stoma, suturing through both anterior and posterior wall during anastomosis, compression of the mesocolon, retro-anastomotic hernia, obstruction of the efferent lobe and narcotic drugs are responsible for gastric retention ${ }^{[14-18]}$. No predisposing factor is detected in patients who have undergone re-operation due to gastric retention, which suggests that there are some anatomical and functional reasons. Probably edema is the leading cause of early postoperative stenosis and obstruction. Another defined cause of delay in gastric emptying is electrical activity created by the ectopic pacemakers in the stomach as a result of disruption of muscle contractions after vagotomy, preventing regular peristaltic waves and delaying the discharge of solid foods in particular $^{[1,17-19]}$. One of the recommended methods to prevent these identified complications is the addition of long intestinal segment Braun (B) anastomosis to this procedure.

In the present study, we evaluated the results of 32 duodenal ulcer patients who underwent elective BTV+GJ with long afferent and efferent loops+B. Early postoperative complications were surgical site infections, delayed gastric emptying and atelectasis, while gastric dullness, episodic diarrhea and Dumping syndrome were among the commonest late postoperative complications (15.3\%, 11.5\% and $7.7 \%$, respectively). When we compare with the literature ${ }^{[20,21]}$, these ratios are lower and acceptable. We did not see any afferent or efferent loop syndromes and blind loop symptoms. In our opinion, ensuring no rotation or folding between the afferent and efferent loops of the jejunum during the creation of GE anastomosis and the addition of $B$ anastomosis to the procedure result in successful outcomes.

In conclusion, although ulcer surgery is rarely performed today after the introduction of the modern anti-ulcer medications, such as proton pump inhibitors, the BTV+GJ+B procedure can be performed safely, especially in intractable cases.

Ethics Committee Approval: Retrospective study.

Peer-review: Externally peer-reviewed.

Conflict of Interest: None declared.

Financial Disclosure: The authors declared that this study received no financial support.

\section{References}

1. Dragstedt LR. The pathogenesis of duodenal and gastric ulcers. Am J Surg 1978;136:286-34. [CrossRef]

2. Flook D, Stoddard CJ. Gastro-oesophageal reflux and oesophagitis before and after vagotomy for duodenal ulcer. $\mathrm{Br} J$ Surg 1985;72:804-7. [CrossRef]

3. Gough MJ. Bile reflux and the gastric mucosal barrier after truncal vagotomy and drainage. Br J Surg 1985;72:853-8.

4. Goligher JC, Pulvertaft CN, Watknson G. Controlled trial of vagotomy and gastro- enterostomy, vagotomy and antrectomy, and subtotal gastrectomy in elective treatment of duodenal ulcer: Interım report. Br Med J 1964;1:455-60. [CrossRef]

5. Cai Z, Zhou Y, Wang C, Yin Y, Yin Y, Shen C, et al. Optimal reconstruction methods after distal gastrectomy for gastric cancer: A systematic review and network meta-analysis. Medicine (Baltimore) 2018;97:e10823. [CrossRef]

6. Lagoo J, Pappas TN, Perez A. A relic or still relevant: the narrowing role for vagotomy in the treatment of peptic ulcer disease. Am J Surg 2014;207:120-6. [CrossRef]

7. Kennedy T, Johnston GW, Love AH, Connell AM, Spencer EF. Pyloroplasty versus gastrojejunostomy. Results of a doubleblind, randomized, controlled trial. Br J Surg 1973;60:949-53.

8. Chen CN, Lee WJ, Lee PH, Chang KJ, Wang SM, Wei TC, et al. Surgical treatment of peptic ulcer disease: changing patterns in the past 40 years. J Formos Med Assoc 1996;95:675-9.

9. Tajima A, Koizumi K, Suzuki K, Higashi N, Takahashi M, Shimada $T$, et al. Proton pump inhibitors and recurrent bleeding in peptic ulcer disease. J Gastroenterol Hepatol 2008;23:S23741. [CrossRef]

10. Schroder VT, Pappas TN, Vaslef SN, De La Fuente SG, Scarborough JE. Vagotomy/drainage is superior to local oversew in patients who require emergency surgery for bleeding peptic ulcers. Ann Surg 2014;259:1111-8. [CrossRef]

11. Ersumo T, Ali A, Kotiso B. Complicated peptic ulcer disease in Tikur Anbessa Hospital, Addis Ababa. Ethiop Med J 2004;42:87-95. 
12. Parr NJ, Grime S, Brownless S, Critchley M, Baxter JN, Mackie CR. Relationship between gastric emptying of liquid and postvagotomy diarrhoea. Br J Surg 1988;75:279-82. [CrossRef]

13. Parr NJ, Grime S, Brownless S, Critchley M, Baxter JN, Mackie CR. Relationship between gastric emptying of liquid and postvagotomy diarrhoea. Br J Surg 1988;75:279-82. [CrossRef]

14. Huang MQ, Li M, Mao JY, Tian BL. Braun enteroenterostomy reduces delayed gastric emptying: A systematic review and meta-analysis. Int J Surg 2015;23:75-81. [CrossRef]

15. LipofT, Shapiro D, Kozol RA. Surgical perspectives in peptic ulcer disease and gastritis. World J Gastroenterol 2006;12:324852. [CrossRef]

16. Greiser WB, Bruner BW, Shamoun JM, Jurkovich GJ, Ferrara JJ. Factors affecting mortality in patients operated upon for complications of peptic ulcer disease. Am Surg 1989;55:7-11.

17. Gururatsakul M, Holloway RH, Bellon M, Bartholomeusz D,
Talley NJ, Holtmann GJ. Complicated and uncomplicated peptic ulcer disease: altered symptom response to a nutrient challenge linked to gastric motor dysfunction. Digestion 2014;89:239-46. [CrossRef]

18. Gayer G, Barsuk D, Hertz M, Apter S, Zissin R. CT diagnosis of afferent loop syndrome. Clin Radiol 2002;57:835-9. [CrossRef]

19. Thirlby RC, Feldman M. Transthoracic vagotomy for postoperative peptic ulcer. Effects on basal, sham feeding- and pentagastrin-stimulated acid secretion, and on clinical outcome. Ann Surg 1985;201:648-55. [CrossRef]

20. Jordan PH Jr, Thornby J. Twenty years after parietal cell vagotomy or selective vagotomy antrectomy for treatment of duodenal ulcer. Final report. Ann Surg 1994;220:283-93.

21. Stabile BE. Surgical treatment of peptic ulceration. Curr Opin Gen Surg 1993:206-15. 